\title{
PERSPECTIVAS DE UTILIZAÇÃO DE OLIVINA E PELLET FEED NA MISTURA DE SINTERIZAÇÃO COMO ALTERNATIVA AO AUMENTO DO TEOR DE SÍLICA DOS MINÉRIOS DE FERRO*
}

Geraldo Timotheo da Rocha ${ }^{1}$ Volner Malini ${ }^{1}$

Arthur Braga Cherem² Tore Rodal ${ }^{3}$

\section{Resumo}

Nos últimos anos ocorreu uma deterioração considerável na qualidade química e granulométrica dos minérios de ferro utilizados na sinterização. Como resultado ficou limitada a utilização de silicatos de $\mathrm{MgO}$ na mistura, devido à elevação excessiva do teor de sílica no sínter, e as siderúrgicas voltaram a utilizar a dolomita como fonte de MgO. A utilização de pellet feed na mistura a sinterizar (natural ou moído) tem se apresentado como uma alternativa à elevação do teor de sílica na sinterização e a eventual redução na produtividade, compensada pela otimização das condições de misturamento. Testes em escala piloto indicam que a eventual redução na produtividade, decorrente da utilização do pellet feed, pode ser compensada pela utilização de olivina na mistura a sinterizar, em substituição à dolomita, com uma otimização do processo e da qualidade do sínter.

Palavras-chave: $\mathrm{MgO}$ no sínter; Olivina; Fundentes na sinterização; Dolomita.

\section{NEW PERSPECTIVES ON THE USAGE OF OLIVINE AND PELLET FEED IN SINTERING MIX AS AN ALTERNATIVE TO THE SILICA CONTENT INCREASE IN IRON ORE}

\begin{abstract}
In recent years there has been a significant deterioration in chemical and particle size quality of iron ore used in sintering process. As a result was limited the use of $\mathrm{MgO}$ silicates in the mixture, due to excessive elevation of the silica content in the sinter, and the companies returned the use of dolomite as a source of $\mathrm{MgO}$. The use of pellet feed in the sinter mixture (natural or ground) has been presented as an alternative to raising the silica content in the sintering and the possible reduction in productivity offset by optimizing the mixing conditions. Pilot scale tests indicate that any reduction in productivity due to the use of pellet feed may be offset by the use of olivine in the sinter mix, replacing dolomite, with an optimization of the process and quality of sinter.
\end{abstract}

Keywords: $\mathrm{MgO}$ in sinter; Olivine; Fluxes in sintering process; Dolomite

1 Engenheiro Metalurgista-Consultor, VFM Consultoria, Membro da ABM, Vitória, ES, Brasil.

2 Engenheiro Metalurgista-Consultor, Chemetals Consultoria, Membro da ABM, Belo Horizonte, MG, Brasil.

3 Engineer-Commercial Manager Steel \& Refractory, Sibelco Europe; Aheim, Norway.

\footnotetext{
* Contribuição técnica ao $44^{\circ}$ Seminário de Redução de Minério de Ferro e Matérias-primas, $15^{\circ}$ Simpósio Brasileiro de Minério de Ferro e $2^{\circ}$ Simpósio Brasileiro de Aglomeração de Minério de Ferro, 15 a 18 de setembro de 2014, Belo Horizonte, MG, Brasil.
} 


\section{INTRODUÇÃO}

\subsection{Utilização de MgO na Sinterização}

Os fundentes têm por função básica escorificar as impurezas da carga do alto-forno, introduzidas pelos minérios e pelo combustível sólido, de modo a permitir a formação de uma escória capaz de absorver o máximo das impurezas presentes, sem comprometer sua fluidez.

A partir dos anos de 1950, com o desenvolvimento do sínter auto fundente, a dolomita passou a ser a principal matéria-prima utilizada como fonte de $\mathrm{MgO}$ na mistura a sinterizar. A literatura especializada enfatiza que, além de ajustar a viscosidade da escória do alto-forno, o MgO eleva as temperaturas de amolecimento e fusão do sínter e minimiza sua degradação sob redução (RDI). Além disso, o MgO favorece a dessulfuração no alto-forno.

$\mathrm{Na}$ década de 1970, estudos em escala piloto, realizados inicialmente no Japão (NSC) e confirmados no Brasil (Usiminas), indicaram que os silicatos de $\mathrm{Fe} \mathrm{e} \mathrm{MgO}$ (olivina, dunito e serpentinito) poderiam ser utilizados em substituição à dolomita com vantagens no processo e na qualidade do produto. A diferença entre os silicatos está mais ligada à mineralogia do que ao seu comportamento. Nos anos seguintes, testes em escala piloto, experiências industriais e ações de controle e ajuste junto aos fornecedores de dunito e serpentinito, otimizaram as características desses fundentes. Como consequência, a utilização das novas alternativas, especialmente o dunito, transformou-se em padrão operacional na siderurgia brasileira, por muitos anos.

Para as sinterizações é importante que se tenha uma maximização da relação $\mathrm{MgO} / \mathrm{SiO}_{2}$, devido à tendência de elevação do teor de sílica dos minérios de ferro e, consequentemente, do sínter. A baixa reatividade da dolomita no processo de sinterização, exigindo um maior aporte térmico, comparativamente às fontes alternativas, prejudica a resistência mecânica e, consequentemente o rendimento do processo, além de afetar negativamente a qualidade metalúrgica do produto (RDI).

Nos últimos 10 anos tem ocorrido uma deterioração considerável na qualidade química e/ou granulométrica das misturas de sínter feed utilizadas por quase todas as siderúrgicas. Como resultado do aumento do teor de sílica dos minérios, ficou inviável a utilização do dunito, devido à elevação excessiva do teor de sílica no sínter. A siderúrgicas voltaram então a utilizar a dolomita, com um controle mais rigoroso na granulometria, e as perdas foram minimizadas pelos menores níveis de produtividade atualmente visados e otimização das condições de homogeneização da mistura.

\subsection{Evolução na Qualidade Química e Granulométrica do Minério de Ferro}

A exaustão das reservas de minério de ferro e a necessidade do desenvolvimento de processos de concentração de itabirito, cada vez mais intensivos, têm conduzido à produção de um sínter feed com maior teor de sílica e/ou granulometria mais fina, uma realidade que tem sido experimenta por praticamente todas as siderúrgicas, mesmo com a busca de fontes alternativas de suprimento de minério de ferro.

A Figura 1 [1] mostra, de forma genérica e qualitativa, a evolução das reservas de minério de ferro do Quadrilátero Ferrífero, a partir da década de 1950, de acordo com um estudo patrocinado pelo Governo, IBS e ABM, em 2008.

\footnotetext{
* Contribuição técnica ao $44^{\circ}$ Seminário de Redução de Minério de Ferro e Matérias-primas, $15^{\circ}$ Simpósio Brasileiro de Minério de Ferro e $2^{\circ}$ Simpósio Brasileiro de Aglomeração de Minério de Ferro, 15 a 18 de setembro de 2014, Belo Horizonte, MG, Brasil.
} 
Como mostrado na figura, a participação da hematita vem se reduzindo à medida que a de itabiriro vai crescendo. De acordo com o autor, os seguintes pontos merecem destaque na análise desses dados:

"As hematitas estão em processo de exaustão nas reservas conhecidas do Quadrilátero e, por conseguinte, deverá haver escassez de granulado, em futuro não muito distante. Sendo mais pobres em ferro, os itabiritos necessitam de usinas mais complexas de beneficiamento, com etapas de concentração mais sofisticadas e com menores índices de recuperação metálica. A geração de minério ultrafino, tipo pellet feed, estará aumentando, principalmente com o advento dos novos projetos".

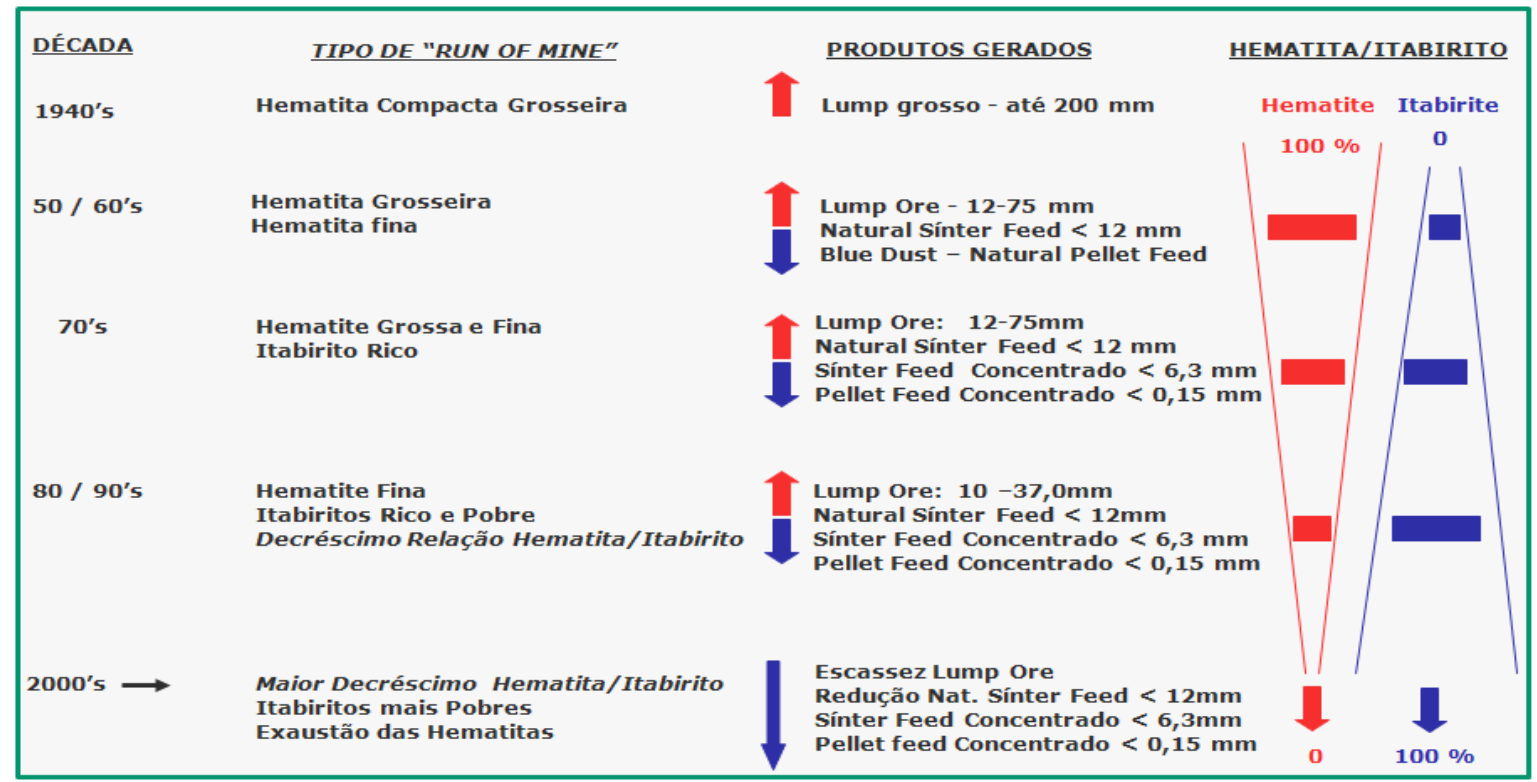

Figura 1 - Evolução qualitativa das reservas de minério de ferro [1].

\subsection{Utilização de Dolomita na Sinterização}

Desde os estudos iniciais realizados na década de 1970, vários trabalhos têm confirmado a influência positiva da utilização de silicatos de $\mathrm{MgO}$ em substituição à dolomita na sinterização. Trabalho recente [2] reafirma a importância da elevação do teor de $\mathrm{MgO}$ na carga metálica do alto-forno e da utilização do dunito como principal fonte desse composto na sinterização ou mesmo direto como granulado na carga do redutor.

No final da década passada a Usiminas iniciou um processo para substituição do dunito pela dolomita, como fonte de $\mathrm{MgO}$ nas misturas de sinterização, diante das perspectivas de elevação do teor de sílica dos minérios de ferro [3]. Após a realização de testes em escala piloto, a prática foi adotada industrialmente, com bons resultados. Observa-se, no entanto, que os testes piloto foram realizados com ênfase na utilização do carregamento segregado, com adição da dolomita na região inferior da camada, onde ocorre maior aporte térmico, além de rigoroso controle da granulometria do fundente. Os bons resultados industriais coincidiram com a redução de produtivadade decorrente das condições de mercado.

Experiência semelhante à da Usiminas foi realizada, quase que à mesma época, pela Arcelor Mittal na Usina de João Monlevade, MG [4], e os resultados, com a utilização de calcário dolomítico como fonte de $\mathrm{MgO}$, indicaram que a manutenção dos níveis de produtividade na sinterização foi obtida, obtendo-se, no entanto, queda na resistência mecânica e aumento no consumo específico de combustível.

* Contribuição técnica ao $44^{\circ}$ Seminário de Redução de Minério de Ferro e Matérias-primas, $15^{\circ}$ Simpósio Brasileiro de Minério de Ferro e $2^{\circ}$ Simpósio Brasileiro de Aglomeração de Minério de Ferro, 15 a 18 de setembro de 2014, Belo Horizonte, MG, Brasil. 
Conclusão semelhante à obtida pela USIMINAS pode ser vista em trabalho recente de pesquisadores da NSC [5]. A dolomita necessita de controle rigoroso de granulometria para substituir, sem prejuízo, os silicatos de MgO (olivina, dunito e serpentinito), normalmente utilizados na siderurgia. Com a utilização de material muito fino sua assimilação é intensa, prejudicando a microestrutura do sínter e com o material mais grosso o aporte térmico é insuficiente para sua reação completa, prejudicando a resistência mecânica e, consequentemente a produtividade.

As informações da literatura indicam, portanto, que a utilização eficiente da dolomita, como fonte de $\mathrm{MgO}$, em substituição aos silicatos, demanda necessariamente um controle muito rigoroso da sua granulometria e do processo de sinterização como um todo, de modo a minimizar os efeitos negativos relacionados anteriormente.

\subsection{Utilização de Pellet Feed na Mistura a Sinterizar}

A deterioração da qualidade química e granulométrica do sínter feed apresenta-se como uma tendência natural. Com a finalidade de buscar alternativas para compensar o empobrecimento do sínter feed, tem sido utilizada, como alternativa, a adição de pellet-feed (natural e moído) à mistura de sinterização, com perspectivas de maior utilização a partir das técnicas de aprimoramento da capacidade de aglomeração a frio.

Recentemente a Usiminas testou em escala piloto [6] a introdução de pellet feed na mistura de sinterização utilizada na Usina de Cubatão, SP. Os resultados indicaram que, com a utilização de $25 \%$ de pellet feed na mistura, em condições normais de misturamento, ocorre uma queda de produtividade de $15 \%$. No entanto, com a utilização do misturamento intensivo, observa-se uma ligeira elevação de produtividade em relação ao nível de referência, com a consequente redução do teor de $\mathrm{SiO}_{2}$ da mistura e sem afetar os demais parâmetros de qualidade do sínter.

\subsection{Perspectivas da Utilização de Olivinas}

Dentre os silicatos usualmente utilizados na sinterização como fonte de $\mathrm{MgO}$, a olivina, do ponto de vista técnico, é a matéria-prima que apresenta as maiores vantagens comparativas: maior relação $\mathrm{MgO} / \mathrm{SiO}_{2}$ e melhor granulometria tamanho e distribuição homogênea).

Com a finalidade de buscar alternativas para compensar o empobrecimento do sínter feed, tendência natural, tem sido utilizada a adição de pellet-feed (natural e moído) à mistura de sinterização. Observa-se igualmente disponibilidade de sínter feed com granulometria adequada, mas com elevado teor de sílica (silicoso). A combinação de uma matéria-prima com essas características com o pellet-feed, não só pode viabilizar a utilização das olivinas, com igualmente tornar-se uma opção estratégica. Pode-se esperar, como resultado, correção da composição química, níveis adequados de produtividade e uma boa qualidade física e metalúrgica do sínter.

No presente estudo, com a finalidade de avaliar melhor essa alternativa e suas potencialidades, optou-se pela realização de testes de sinterização em escala piloto.

\footnotetext{
* Contribuição técnica ao $44^{\circ}$ Seminário de Redução de Minério de Ferro e Matérias-primas, $15^{\circ}$ Simpósio Brasileiro de Minério de Ferro e $2^{\circ}$ Simpósio Brasileiro de Aglomeração de Minério de Ferro, 15 a 18 de setembro de 2014, Belo Horizonte, MG, Brasil.
} 


\section{MATERIAIS E MÉTODOS}

\subsection{Misturas Testadas}

Os testes de sinterização em escala piloto são uma ferramenta bastante segura para avaliação de novas misturas alternativas na sinterização. A extrapolação dos resultados obtidos nos testes garante segurança na adoção de novas alternativas. Algumas siderúrgicas condicionam a utilização de novas alternativas à realização preliminar de ensaios em escala piloto de sinterização.

Com a finalidade de avaliar a utilização da olivina como alternativa importante à elevação do teor de sílica dos minérios de ferro atualmente disponíveis para sinterização foram realizados testes de sinterização em escala piloto. Os ensaios foram realizados na Máquina Piloto de Sinterização da MINITEC, localizada em Divinópolis, MG. Os ensaios foram realizados em duas etapas.

Na primeira etapa, Etapa 1, foi avaliada uma mistura padrão de sinterização (Sínter Feed A), utilizada como referência, e que busca simular a produção de um sínter a ser utilizado como principal componente da carga metálica (80 a 85\%) do alto-forno. Essa mistura de referência utiliza dolomita como fonte de $\mathrm{MgO}$, que é o padrão adotado pela maior parte das siderúrgicas no Brasil. Como alternativa, essa mistura foi comparada com uma mistura de mesma composição química (Mistura 1) e que utiliza olivina como fonte de MgO. Nessa mistura alternativa ocorreu a introdução de pellet-feed concentrado para manutenção dos teores de sílica da mistura em relação ao nível de referência.

Para as misturas testadas na Etapa 1 etapa foram visados: basicidade $\left(\mathrm{CaO} / \mathrm{SiO}_{2}\right)$ de $1,75, \mathrm{MgO}$ de $1,25 \%$ e $\mathrm{SiO}_{2}$ de $5,35 \%$.

Numa segunda etapa, Etapa 2, utilizando-se uma mistura de minérios de ferro diferente da anterior (Sínter Feed B), foi realizada uma comparação direta entre duas misturas de sinterização (Misturas 2 e 3) que utilizam dolomita ou olivina como fonte de MgO. Nesse caso o teor de sílica das misturas foi mantido constante através da adição de areia fina quando da utilização de dolomita à mistura de sinterização. Nessa segunda etapa a composição química do sínter corresponde a uma carga metálica com cerca de $60 \%$ de sínter e com a utilização maior de carga metálica complementar.

Para as misturas testadas na Etapa 2 foram visados: basicidade $\left(\mathrm{CaO} / \mathrm{SiO}_{2}\right)$ de 1,90, $\mathrm{MgO}$ de $1,65 \%$ e $\mathrm{SiO}_{2}$ de $5,53 \%$.

A Tabela 1 mostra a composição das diferentes misturas testadas nos ensaiose a Tabela 2 a composição química das diferentes misturas.

\footnotetext{
* Contribuição técnica ao $44^{\circ}$ Seminário de Redução de Minério de Ferro e Matérias-primas, $15^{\circ}$ Simpósio Brasileiro de Minério de Ferro e $2^{\circ}$ Simpósio Brasileiro de Aglomeração de Minério de Ferro, 15 a 18 de setembro de 2014, Belo Horizonte, MG, Brasil.
} 
Tabela 1. Misturas utilizadas nos ensaios de sinterização (\% - base seca)

\begin{tabular}{|c|c|c|c|c|}
\hline \multirow{2}{*}{$\begin{array}{c}\text { Matéria-Prima } \\
(\%)\end{array}$} & \multicolumn{2}{|c|}{ Etapa 1} & \multicolumn{2}{|c|}{ Etapa 2} \\
\hline & $\begin{array}{l}\text { Referência } \\
\text { (dolomita) }\end{array}$ & $\begin{array}{c}\text { Mistura } 1 \\
\text { (olivina) }\end{array}$ & $\begin{array}{c}\text { Mistura } 2 \\
\text { (olivina) }\end{array}$ & $\begin{array}{l}\text { Mistura } 3 \\
\text { (dolomita) }\end{array}$ \\
\hline Sinter feed $A$ & 82,57 & 62,1 & - & - \\
\hline Pellet feed & - & 20,7 & - & - \\
\hline Sinter feed B & - & - & 79,72 & 74,95 \\
\hline Calcário fino & 10,3 & 13,67 & 17,11 & 16,55 \\
\hline Olivina & - & 2,03 & 2,67 & \\
\hline Dolomita fina & 5,63 & - & - & 6,95 \\
\hline Cal fina & 1,5 & 1,5 & 0,5 & 0,5 \\
\hline Areia fina & - & - & - & 1,05 \\
\hline $\begin{array}{l}\text { Rendimento } \\
\text { químico (\%) }\end{array}$ & 91,27 & 92,72 & 91,32 & 88,60 \\
\hline
\end{tabular}

Tabela 2. Composição química das misturas de sínter produzidos

\begin{tabular}{|c|c|c|c|c|}
\hline $\begin{array}{c}\text { Elemento/Composto } \\
\text { (\%) }\end{array}$ & Base & Mix 1 & Mix 2 & Mix 3 \\
\hline $\mathbf{F e}$ & 57,8 & 58,4 & 55,8 & 54,3 \\
\hline $\mathbf{M g O}$ & 1,25 & 1,25 & 1,65 & 1,65 \\
\hline $\mathbf{C a O}$ & 9,36 & 9,37 & 10,51 & 10,5 \\
\hline $\mathbf{S i O}_{\mathbf{2}}$ & 5,35 & 5,35 & 5,53 & 5,52 \\
\hline $\mathbf{A l}_{\mathbf{2}} \mathbf{O}_{3}$ & 0,95 & 0,82 & 1,69 & 1,64 \\
\hline $\mathbf{P}$ & 0,06 & 0,06 & 0,04 & 0,04 \\
\hline $\mathbf{i}_{\mathbf{2}} \mathbf{( C a O}_{\mathbf{S i O}} \mathbf{)}$ & 1,75 & 1,75 & 1,90 & 1,90 \\
\hline $\begin{array}{c}\text { Rendimento químico } \\
\text { da sinterização (\%) }\end{array}$ & 91,27 & 92,72 & 91,32 & 88,60 \\
\hline
\end{tabular}

\subsection{Composição Química e Granulométrica das Matérias-Primas}

A Tabelas 3 e 4 mostram as composições química e granulométrica das matériasprimas utilizadas nos ensaios de sinterização em escala piloto.

Tabela 3. Composição química das matérias-primas utilizadas nos ensaios (\%)

\begin{tabular}{|l|c|c|c|c|c|c|c|c|}
\hline Matéria-prima & $\mathrm{Fe}$ & $\mathrm{Mn}$ & $\mathrm{SiO}_{2}$ & $\mathrm{Al}_{2} \mathrm{O}_{3}$ & $\mathrm{CaO}$ & $\mathrm{MgO}$ & $\mathrm{P}$ & $\mathrm{PPC}$ \\
\hline Sinter feed A & 63,50 & - & 5,58 & 0,91 & - & - & 0,063 & 2,14 \\
\hline Pellet feed & 67,82 & 0,05 & 1,60 & 0,35 & 0,11 & 0,07 & 0,023 & 0,2 \\
\hline Sinter feed B & 64,25 & 0,09 & 4,74 & 1,71 & 0,04 & 0,04 & 0,04 & 1,6 \\
\hline Calcário fino & - & - & 2,15 & 0,30 & 53,64 & 0,30 & 0,04 & 42,8 \\
\hline Cal fina & - & - & 1,20 & 0,40 & 94,50 & 0,55 & 0,07 & 3,0 \\
\hline Dolomita & 3,0 & & 2,69 & 0,10 & 29,4 & 18,3 & - & 44,4 \\
\hline Olivina & 5,0 & - & 40,0 & 0,5 & 0,20 & 49,0 & - & 2,0 \\
\hline Areia fina & - & - & 95,0 & - & - & - & - & 1,0 \\
\hline Coque fino & - & - & 8,7 & 5,4 & - & $\begin{array}{c}\text { Carbono fixo }=75 \% \\
\text { Cinza }=22 \%\end{array}$ \\
\hline
\end{tabular}

\footnotetext{
* Contribuição técnica ao $44^{\circ}$ Seminário de Redução de Minério de Ferro e Matérias-primas, $15^{\circ}$ Simpósio Brasileiro de Minério de Ferro e $2^{\circ}$ Simpósio Brasileiro de Aglomeração de Minério de Ferro, 15 a 18 de setembro de 2014, Belo Horizonte, MG, Brasil.
} 
Tabela 4. Granulometria das matérias-primas ( $\mathrm{mm} / \mathrm{mesh}$ - \% retida acumulada)

\begin{tabular}{|c|c|c|c|c|c|c|c|c|c|}
\hline Matéria-prima & 9,52 & 6,35 & 4,76 & 2,83 & 1,00 & 100 & 150 & 200 & $<200$ \\
\hline Sinter feed $A$ & 2,6 & 11,2 & 16,5 & 31,2 & 53,7 & 72,6 & 81,0 & - & 100,0 \\
\hline Pellet feed & \multicolumn{5}{|c|}{10} & \multicolumn{4}{|c|}{100} \\
\hline Sinter feed B & \multicolumn{4}{|c|}{58,2} & & 71 & \multicolumn{3}{|c|}{100} \\
\hline Calcário fino & \multicolumn{4}{|c|}{10} & \multicolumn{2}{|c|}{75} & \multicolumn{3}{|c|}{100} \\
\hline \multicolumn{10}{|l|}{ Cal fina } \\
\hline Dolomita & \multicolumn{4}{|c|}{10} & \multicolumn{2}{|c|}{70} & \multicolumn{3}{|c|}{100} \\
\hline Olivina & 0 & 1 & 3 & 9 & 18 & 37 & 63 & 94 & 100 \\
\hline Areia fina & \multicolumn{9}{|c|}{$<2,00 \mathrm{~mm}$} \\
\hline Coque fino & 0,0 & 0,3 & 8,2 & 27,6 & 57,4 & 88,4 & 94,4 & 95,3 & 100,0 \\
\hline
\end{tabular}

\subsection{Equipamento e Metodologia dos Ensaios de Sinterização}

A metodologia de avaliação da sinterabilidade consiste na realização de queimas, em escala piloto, de misturas de minérios, fundentes, combustível e finos de retorno. Parâmetros básicos dos testes na Máquina Piloto de Sinterização da MINITEC:

- Seção transversal da panela: circular com área de 0,1 $\mathrm{m}^{2}$.

Altura total da camada: $550 \mathrm{~mm}$ (mistura + bedding).

Altura do bedding: $50 \mathrm{~mm}(=3 \mathrm{~kg})$.

- Umidade das misturas: entre 6 e 7,0\%, se mistura hematítica ou hidratada.

- Sucção (pressão negativa) durante a ignição: $\sim 750$ mm $\mathrm{m}_{2} \mathrm{O}$.

- Sucção durante a queima: $1.400 \mathrm{mmH}_{2} \mathrm{O}$ (constante, para permitir comparação de diferentes misturas).

- Tempo de ignição: 1,0 minuto.

- Combustível de ignição: gás liquefeito de petróleo (GLP).

Todas as misturas foram preparadas no misturador de tambor, com tempo total de misturamento de 4 minutos. O retorno introduzido é pré-fixado e corresponde a $25 \%$ da mistura total, sendo sua granulometria preparada em $100 \%<6,3 \mathrm{~mm}$. Para execução dos testes são realizadas inicialmente queimas para obtenção dos finos de retorno. Nessas queimas a umidade de trabalho das misturas é avaliada. A degradação do bolo de sínter, visando simular a britagem, quedas e peneiramentos a que o sínter é submetido em escala industrial, é definida como segue:

- Uma queda de 2,0 metros, quando da descarga do bolo de sínter da panela, seguida de cinco voltas no aparelho de teste de tamboramento.

- Peneiramento manual em malhas de 50, 25, 10 e 6,3 mm. O retorno produzido é o passante na malha de $6,3 \mathrm{~mm}$.

A figura 1 ilustra, através de fotografias, a Máquina Pilota de Sinterização da MINITEC, situada na cidade de Divinópolis, MG, junto ao Distrito Industrial.

\footnotetext{
* Contribuição técnica ao $44^{\circ}$ Seminário de Redução de Minério de Ferro e Matérias-primas, $15^{\circ}$ Simpósio Brasileiro de Minério de Ferro e $2^{\circ}$ Simpósio Brasileiro de Aglomeração de Minério de Ferro, 15 a 18 de setembro de 2014, Belo Horizonte, MG, Brasil.
} 
se concluir que os resultados para as duas misturas testadas nessa etapa são equivalentes,

\subsection{Comparação entre a Utilização de Olivina e Dolomita - Etapa 2}

Analisando-se os resultados mostrados na Tabela 4 observa-se que os valores de coke-rate e produtividade dessas misturas vêm apenas confirmando o já constatado repetidamente na literatura: silicatos magnesianos (olivina, dunito, serpentinito) levam a melhores resultados que a dolomita. Para as misturas em questão a diferença foi muito significativa, evidenciando ser viável a introdução de considerável proporção de pellet feed, possivelmente até com redução de custo de aquisição da matéria-prima, como mostrado na Etapa1 do presente trabalho. O resultado dessa etapa apresenta ainda uma pequena elevação na resistência mecânica do sínter, com a utilização de olivina, reforçando a tendência global observada nos testes.

Existe unidade nas informações da literatura de que o efeito negativo de uso da dolomita é tanto maior quanto maior seja a necessidade de produção das máquinas de sinterização. Máquinas com baixa produtividade tendem a absorver melhor a dolomita, pelo fato de haver melhores condições cinéticas para as reações do $\mathrm{MgO}$ proveniente da dolomita e é feito um acompanhamento sistemático das temperaturas dos gases de exaustão, pelo fato de o pico de temperatura definir o tempo de sinterização. Análises sistemáticas desses perfis, para diferentes misturas, podem indicar o fenômeno que está associado às alterações do processo. Constatou-se nos testes realizados que para as Misturas 2 e 3 os perfis de temperatura apresentam temperatura de pico da ordem de $250^{\circ} \mathrm{C}$ para a olivina e de $\sim 200^{\circ} \mathrm{C}$ para a dolomita, para um mesmo teor de combustível das misturas. Este fato pode estar evidenciando o consumo adicional de coque para a decomposição do carbonato. Como houve perda de resistência do sínter e elevação do retorno, um aumento adicional no percentual de coque dessa mistura deve levar a um maior coke-rate, acentuando a desvantagem de uso desse material.

\subsection{Rendimento do Sínter - Análises Complementares}

Analisando-se os dados de rendimento químico da Tabela 1, constata-se um dos aspectos negativos do uso de dolomita na sinterização: há uma significativa diminuição no rendimento químico, tanto maior quanto maior seja a utilização de dolomita. Essa perda de rendimento é decorrente da calcinação do carbonato e consequente perda de massa da mistura após a sinterização. A consequência direta disso é perda de massa de sinter para cada tonelada de mistura introduzida na máquina, independentemente das perdas decorrentes de despoeiramento, transporte e manuseio. Para um mesmo preço do ponto de $\mathrm{MgO}$ do fundente, a dolomita implica necessariamente em perda de produção decorrente dessa perda de massa. Junto com a perda de produção ocorre igualmente uma elevação do custo devido à elevação do coke-rate, apenas em função dessa perda de massa, sem se considerar a decomposição térmica do carbonato.

As diferenças entre os resultados obtidos nas Etapas 1 e 2 podem ser atribuídos às características das amostras de sínter feed utilizadas e à composição química dos sínteres produzidos.

\footnotetext{
* Contribuição técnica ao $44^{\circ}$ Seminário de Redução de Minério de Ferro e Matérias-primas, $15^{\circ}$ Simpósio Brasileiro de Minério de Ferro e $2^{\circ}$ Simpósio Brasileiro de Aglomeração de Minério de Ferro, 15 a 18 de setembro de 2014, Belo Horizonte, MG, Brasil.
} 


\section{CONCLUSÃO}

Embora, em alguns casos, seja considerado inevitável o uso de dolomita na mistura de sinterização, devido ao atual elevado teor de sílica dos minérios de ferro, é conveniente que essa definição se dê considerando-se o uso de pellet feed para essa correção, preferencialmente ao uso de dolomita, devido à elevação de custos por causa da perda de resistência do sínter e da produtividade de máquina.

Sinterizações com misturamento otimizado (Misturamento Intensivo ou HPS) têm maior flexibilidade para uso de pellet feed, sem perda de produção.

A comparação pura do uso de olivina e dolomita na sinterização veio confirmar as informações da literatura técnica de que o uso de dolomita deve ser evitado, sempre que possível.

Em termos químicos a dolomita leva a uma redução de rendimento químico do processo, por si só responsável por perda de produção, decorrente do menor peso de sínter produto.

Dentre os silicatos de $\mathrm{MgO}$, a olivina apresenta, do ponto de vista técnico, vantagens competitivas relacionadas com a granulometria mais adequada e estável e melhor relação $\mathrm{MgO} / \mathrm{SiO}_{2}$.

\section{REFERÊNCIAS}

1 Mourão JM. Minério de Ferro e Pelotas - Situação Atual e Tendências 2025. Estudo Prospectivo do Setor Siderúrgico: 2008. Brasília: Centro de Gestão e Estudos Estratégicos, 2008.

2 Caballero R, Vervenne R, Arango PC, Martinez J. Benefitts of dunite as MgO addiction for sinter and blast furnace. In: Associação Brasileira de Metalurgia, Materiais e Mineração ABM. Anais do 40th International Meeting on Ironmaking and $11 \mathrm{~h}$ International Symposium on Iron Ore, Belo Horizonte, MG, Brazil, September 2010.

3 Scudeller LAM, Silva BV, Honorato EP, Tetti U. Utilização da dolomita como fonte exclusiva nas sinterizações da Usiminas. In: Associação Brasileira de Metalurgia, Materiais e Mineração - ABM. Anais do $9^{\circ}$ Simpósio de Minério de Ferro, Ouro Preto, MG, Brasil, Novembro de 2009.

4 Pimenta FV, Souza JA, Marques MB, Bicalho RM, Custódio JD, Ambrósio C. Elevação do teor de $\mathrm{MgO}$ no sínter com o aumento da utilização de calcário dolomítico. In: Associação Brasileira de Metalurgia, Materiais e Mineração ABM. Anais do $40^{\circ}$ Seminário de Redução de Minério de Ferro e Matérias-Primas, ABM. Belo Horizonte, MG, Brasil. Setembro, 2010.

5 Higuchi K, Tanaka T, Sato T. Reaction behavior of dolomite accompanied with formation of magnetite solid solution in Iron ore sintering process. ISIJ International, Vol. 47 (2007), No. 5, pp. 669-678.

6 Barbosa AA, Scudeller LAM, Tetti U, Silva BV. Utilização de pellet feed em misturas a sinterizar da Usiminas. In: Associação Brasileira de Metalurgia, Materiais e Mineração ABM. Anais do $40^{\circ}$ Seminário de Redução de Minério de Ferro e Matérias-Primas, ABM. Belo Horizonte, MG, Brasil. Setembro, 2010.

\footnotetext{
* Contribuição técnica ao $44^{\circ}$ Seminário de Redução de Minério de Ferro e Matérias-primas, $15^{\circ}$ Simpósio Brasileiro de Minério de Ferro e $2^{\circ}$ Simpósio Brasileiro de Aglomeração de Minério de Ferro, 15 a 18 de setembro de 2014, Belo Horizonte, MG, Brasil.
} 